\title{
Executive Function and Attention Are Preserved in Older Surgically Menopausal Monkeys Receiving Estrogen or Estrogen Plus Progesterone
}

\author{
Mary Lou Voytko, ${ }^{1,2}$ Rhonda Murray, ${ }^{1}$ and Casey J. Higgs ${ }^{1}$ \\ ${ }^{1}$ Department of Neurobiology and Anatomy and ${ }^{2}$ Interdisciplinary Neuroscience Program, Wake Forest University School of Medicine, Winston-Salem, \\ North Carolina 27157
}

\begin{abstract}
Animal models of menopause have been used to further define the cognitive processes that respond to hormone therapy and to investigate parameters that may influence the cognitive effects of estrogen. Many investigations in animals have focused on memory; however, the effects of hormone therapy on executive function and attention processes have not been well studied. Thus, the purpose of this set of investigations was to assess the effects of estrogen therapy alone or with progesterone on executive and attention processes in middleaged ovariectomized monkeys. Monkeys were preoperatively trained on a modified version of the Wisconsin card sort task and on a visual cued reaction time task. Hormone therapy was initiated at the time of ovariectomy and cognitive function was reassessed at 2, 12 , and 24 weeks postoperatively. Relative to monkeys receiving either of the estrogen therapies, monkeys receiving placebo were impaired in their ability to shift a cognitive set in the Wisconsin card sort task and were impaired in shifting visuospatial attention in the visual cued reaction time task. Our findings are consistent with clinical studies that indicate that hormone therapy can improve executive function and attention processes in postmenopausal women.
\end{abstract}

\section{Introduction}

Ovarian hormones modulate many systems and circuits in the brain that are important for cognitive function (McEwen, 2001; Woolley, 2007). Executive function and attention processes are among some of the cognitive domains that are enhanced by hormone therapy (HT) in postmenopausal women. The term executive function refers to a larger collection of high level cognitive processes that includes reasoning, problem-solving, and cognitive flexibility (i.e., cognitive set-shifting or attentional setshifting). The Wisconsin card sorting task (WCST) (Berg, 1948; Milner, 1963) traditionally has been used to assess cognitive setshifting in humans and performance on the task is improved in postmenopausal women on HT (Schmidt et al., 1996; Dunkin et al., 2005; Erickson et al., 2007). Attention is also a term that refers to many different processes and different types of attention have been measured in postmenopausal women, including vigilance (sustained attention) and visual search (selective attention). Both of these types of attention processes were improved by HT in some studies of postmenopausal women (Vanhulle and Demol, 1976; Fedor-Freybergh, 1977; Schmidt et al., 1996; Rudolph et al., 2000; Smith et al., 2001), but not all studies (Polo-Kantola et al., 1998; Binder et al., 2001; Alhola et al., 2006; Kurt et al., 2006).

Received April 2, 2009; revised June 17, 2009; accepted July 22, 2009.

This research was supported by Grant AG13204 from the National Institute on Aging.

Correspondence should be addressed to Mary Lou Voytko, Department of Neurobiology and Anatomy, Wake Forest University School of Medicine, Medical Center Boulevard, Winston-Salem, NC 27157. E-mail: mlvoytko@wfubmc.edu.

D0I:10.1523/JNEUROSCI.1591-09.2009

Copyright $\odot 2009$ Society for Neuroscience $\quad$ 0270-6474/09/2910362-09\$15.00/0
Animal models of menopause have been used to further define the cognitive processes that respond to HT and to investigate parameters that may influence the cognitive effects of HT. Although many animal studies have focused on memory, the effects of HT on executive function and attention processes have not been well studied. Indeed, these cognitive functions have not been examined at all in ovariectomized (OVX) rodents. In monkeys, measures of cognitive flexibility were not affected by either OVX or estrogen alone therapy (ET) in young (Voytko, 2000) or older (Lacreuse et al., 2000, 2004) monkeys. In contrast, visuospatial attention was disrupted after OVX in young monkeys and this impairment was reversed with ET (Voytko, 2002).

In a series of investigations, we have been examining the effects of ET and estrogen plus progesterone therapy $(\mathrm{E}+\mathrm{P})$ on cognitive function of middle-aged surgically menopausal monkeys. We previously reported that visual recognition memory was preserved by ET or $\mathrm{E}+\mathrm{P}$ in middle-aged surgically menopausal monkeys (Voytko et al., 2008). The purpose of this current set of investigations was to assess the effects of these therapies on executive function and attention processes in middle-aged menopausal monkeys to further our understanding of how these cognitive processes respond to HT in primates. To assess executive function, a modified version of the WCST was used to measure cognitive set-shifting, and a visuospatial cued reaction time task (VCRTT) was used to measure shifting of visuospatial attention. Thus, the ability to shift between perceptual/ stimulus dimensions or between spatial locations was evaluated in middle-aged menopausal monkeys. We predicted that both shifting of cognitive sets (WCST) and shifting of spatial attention (VCRTT) would be better in monkeys receiving ET and/or E $+\mathrm{P}$ compared with monkeys receiving placebo. 


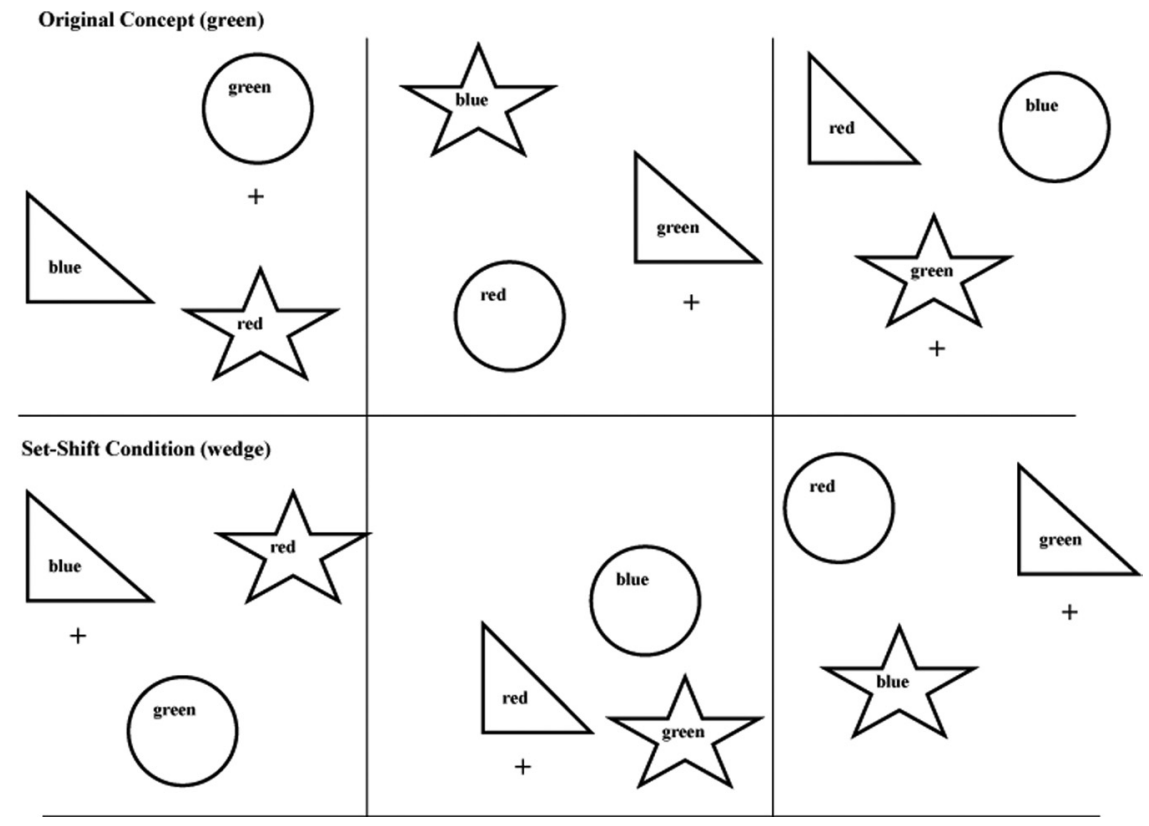

Figure 1. Schematic of the computerized WCST. Each block illustrates an individual trial of the WCST. Three stimuli that vary in $1-3$ shapes and 1-3 colors are shown on each trial. The top three blocks illustrate trials in which the monkey learns an original concept (in this case the color green is relevant to receive a reward, + ) and the bottom three blocks illustrate trials in which the monkey learns a conceptual set-shift (the wedge shape is now relevant to receive a reward).
Postoperative (postop) testing of monkeys receiving $\mathrm{ET}$ or $\mathrm{E}+\mathrm{P}$ was conducted throughout their treatment schedule and was not confined to only a particular phase of their schedule to mirror the conditions that hormonally treated postmenopausal women normally experience in their daily lives. Monkeys were randomized to treatment group based on their preoperative (preop) mean performance on the delayed response and delayed matching-to-sample tasks (Voytko et al., 2008).

\section{Ovariectomy}

A staff veterinarian ovariectomized the monkeys using sterile surgical procedures. The monkeys were sedated with ketamine (5-10 $\mathrm{mg} / \mathrm{kg}$, i.m.), the trachea intubated, and the animals maintained on $2.5 \%$ isoflurane and oxygen during the surgery. A midline incision was made, the ovaries were exteriorized, the vasculature was ligated, the ovaries removed, and the incision was then sutured closed. The monkeys were monitored postoperatively until recovered from anesthesia and then on a daily basis until sutures were removed. Butorphanol $(0.025 \mathrm{mg} / \mathrm{kg}, \mathrm{i} . \mathrm{m}$.) was administered once to alleviate pain at 3-4 h after surgery. Surgically related postoperative complications were not noted in any of the monkeys.

\section{Hormone treatments}

Table 1. Stimuli used in each assessment phase of WCST

\begin{tabular}{|c|c|c|}
\hline Test phase & Colors & Shapes \\
\hline \multirow[t]{3}{*}{ Preoperative } & Burgundy (+ for shift) & Horseshoe (+ for original concept) \\
\hline & Light blue & Lighting bolt \\
\hline & Mint green & Circle with slash in the center \\
\hline \multirow[t]{3}{*}{ Postop\#1 } & Bright red (+ for original concept) & Cylinder (+ for shift) \\
\hline & Amber & Airplane \\
\hline & Lavender & Seven-point star \\
\hline \multirow[t]{3}{*}{ Postop\#2 } & Bright yellow (+ for shift) & Pac-Man (+ for original concept) \\
\hline & White & Right arrowhead \\
\hline & Deep purple & File symbol \\
\hline \multirow[t]{3}{*}{ Postop\#3 } & Pale pink ( + for shift) & Folded banner (+ for original concept) \\
\hline & Deep fuschia & Pipe \\
\hline & Steel Blue & Asterisk \\
\hline
\end{tabular}

+ , Correct examplar.

\section{Materials and Methods}

\section{Subjects}

Twenty-four female rhesus (Macaca mulatta) monkeys (mean \pm SEM at time of OVX and treatment initiation: $19.7 \pm 0.5$ years) were the subjects of these experiments. These monkeys also had been tested on a delayed matching-to-sample task and on a delayed response task as part of a larger study investigating the cognitive effects of HT in middle-aged female monkeys (Voytko et al., 2008). The animals were individually housed in a climate-controlled room. Water was available ad libitum and rations of monkey chow were provided after the daily behavioral sessions. They received environmental enrichment in the form of novel toys and foods regularly. All procedures involving animals were conducted according to the National Institute of Health Guide for the Care and Use of Laboratory Animals (NIH Publications No. 80-23) and approved by the Wake Forest University School of Medicine Animal Care and Use Committee. All efforts were made to minimize the number of animals used and their suffering.

\section{Experimental design}

Monkeys were trained and tested on the tests of executive function and attention before ovariectomy and initiation of HT, and were reexamined at 2, 12, and 24 weeks after surgery. Animals were tested $5 \mathrm{~d}$ per week.
At the time of ovariectomy, monkeys were subcutaneously implanted with a $3.5 \mathrm{~cm}$ length of either empty SILASTIC tubing $(0.335 \mathrm{~cm}$ inner diameter and $0.465 \mathrm{~cm}$ outer diameter) [placebo group (PL); $n=7$ ] or tubing containing a $3 \mathrm{~cm}$ packed column of $17 \beta$-estradiol $(n=17$; Steraloids). Implants of this size have been used successfully in previous monkey studies and have remained viable for $>14$ months after implantation (Voytko, 2000, 2002; Voytko et al., 2008). These implants delivered and maintained mean basal estradiol (E2) levels of $63.5 \pm 3.6 \mathrm{pg} / \mathrm{ml}$ (Voytko et al., 2008). All monkeys with E2 implants also received an injection of estradiol valerate $(0.10-0.20 \mathrm{mg} / \mathrm{cc}$, Pfizer, $)$ on day 12 to simulate the preovulatory peak in E2 that normally occurs in the menstrual cycle. These injections achieved mean E2 peaks of $536.31 \pm 24.6$ $\mathrm{pg} / \mathrm{ml}$ in these animals (Voytko et al., 2008). Nine of the monkeys receiving E2 implants comprised the ET group while the remaining eight monkeys with implants comprised the $\mathrm{E}+\mathrm{P}$ group and were given oral doses of progesterone $(0.2 \mathrm{mg} / \mathrm{kg}$, Prometrium, USP, Solvay Phamaceuticals) for $12 \mathrm{~d}$ beginning on day 16 . Oral dosing of progesterone (P4) was chosen because of the reoccurring cyclical nature of the therapy schedule of this hormone. The P4 dosing schedule duration and start day was based on the normal menstrual cycle of macaque monkeys (Goodman et al., 1977; Downs and Urbanski, 2006). The P4 was placed in various foods or treats for dosing and each animal was closely observed during the dosing to ensure that the foods/treats were totally consumed. This schedule of E2 injections and P4 dosing was repeated monthly through the study.

\section{Hormone assays}

Levels of E2 and P4 were monitored throughout the study. Awake monkeys were placed in a specially constructed transfer cage where blood was drawn from the saphenous vein. Monkeys receiving E2 had blood samples taken the day before the $\mathrm{E} 2$ injection to determine $\mathrm{E} 2$ levels delivered by the implants. After the $\mathrm{E} 2$ injection, blood was again drawn $6 \mathrm{~h}$ later to determine peak levels of $\mathrm{E} 2$ attained by the injection. For $\mathrm{E}+\mathrm{P}$ monkeys, blood was also drawn on days 1, 6, and 12 of P4 dosing to determine levels of $\mathrm{P} 4$, with another blood sample drawn $24 \mathrm{~h}$ after the final $\mathrm{P} 4$ dose to verify that P4 levels were no longer elevated. This schedule of blood sampling was repeated monthly through the course of the study. Blood was collected in sterile serum tubes, allowed to clot, centrifuged, and then serum was aliquoted into separate tubes and frozen at $-20^{\circ} \mathrm{C}$. Serum 
Table 2. Group effect sizes

\begin{tabular}{|c|c|c|}
\hline & Dependent measure & Cohen'sd \\
\hline \multicolumn{3}{|l|}{ Postop 1} \\
\hline \multirow[t]{2}{*}{ WCST learn original concept } & Trials & 0.09 \\
\hline & Errors & 0.21 \\
\hline \multirow[t]{6}{*}{ WCST conceptual set-shift } & Trials & $0.74^{*}$ \\
\hline & Errors & 0.62 \\
\hline & Perseverative errors & $0.76^{*}$ \\
\hline & Stage I blocks & 0.44 \\
\hline & Stage II blocks & $0.95^{*}$ \\
\hline & Stage III blocks & $0.94^{*}$ \\
\hline \multirow[t]{3}{*}{ VCRTT } & Validity & 0.31 \\
\hline & Benefits & $0.84^{*}$ \\
\hline & Costs & $1.08^{*}$ \\
\hline \multicolumn{3}{|l|}{ Postop 2} \\
\hline \multirow[t]{2}{*}{ WCST learn original concept } & Trials & 0.35 \\
\hline & Errors & 0.21 \\
\hline \multirow[t]{6}{*}{ WCST conceptual set-shift } & Trials & 0.56 \\
\hline & Errors & 0.52 \\
\hline & Perseverative errors & 0.54 \\
\hline & Stage I blocks & 0.55 \\
\hline & Stage II blocks & $0.84^{*}$ \\
\hline & Stage III blocks & 0.11 \\
\hline \multirow[t]{3}{*}{ VCRTT } & Validity & 0.54 \\
\hline & Benefits & 0.59 \\
\hline & Costs & 0.12 \\
\hline \multicolumn{3}{|l|}{ Postop 3} \\
\hline \multirow[t]{2}{*}{ WCST learn original concept } & Trials & 0.10 \\
\hline & Errors & 0.35 \\
\hline \multirow[t]{6}{*}{ WCST conceptual set-shift } & Trials & 0.20 \\
\hline & Errors & 0.29 \\
\hline & Perseverative errors & 0.22 \\
\hline & Stage I blocks & 0.61 \\
\hline & Stage II blocks & 0.10 \\
\hline & Stage III blocks & 0.24 \\
\hline \multirow[t]{3}{*}{ VCRTT } & Validity & 0.07 \\
\hline & Benefits & 0.22 \\
\hline & Costs & 0.15 \\
\hline
\end{tabular}

*Large effect size.

levels of E2 and P4 were measured with a Roche Diagnostics Elecsys 2010 clinical assay platform by the Oregon National Primate Research Center Endocrine Services Core Laboratory. These assays had been previously validated against traditional extraction radioimmunoassays (Hess et al., 1981). The sensitivity for $\mathrm{E} 2$ was $12 \mathrm{pg} / \mathrm{ml}$ and for $\mathrm{P} 4$ was $0.05 \mathrm{ng} / \mathrm{ml}$. The coefficient of variation for both hormones was $<10 \%$.

\section{Behavioral apparatus}

Computer-controlled apparatuses with touchscreen monitors were used to behaviorally train and test the monkeys (Voytko et al., 2008). For all tasks, auditory feedback was provided by the sound of chimes for correct responses and a low-pitched tone for incorrect responses. Visual feedback on all tasks consisted of the monitor screen turning black after correct responses and turning blue after incorrect responses. The monitor screen turned red to signal the end of the test session.

\section{Behavioral tasks}

WCST. This task is based on one used to assess the ability to abstract, maintain, and shift a cognitive set in humans (Berg, 1948; Milner, 1963) and was modified for use in monkeys (Moore et al., 2005, 2006). Dr. James Herndon at the Yerkes National Primate Research Center (Emory University, Atlanta, GA) graciously provided touchscreen computer software for the WCST pretraining simple three choice discrimination task and the WCST itself. In these tasks, three stimuli that varied by shape and color were displayed.

Before training on the WCST task, the monkeys learned a simple three choice discrimination task to establish that the monkeys could discriminate among three stimuli that differed by color (yellow, purple, aqua)
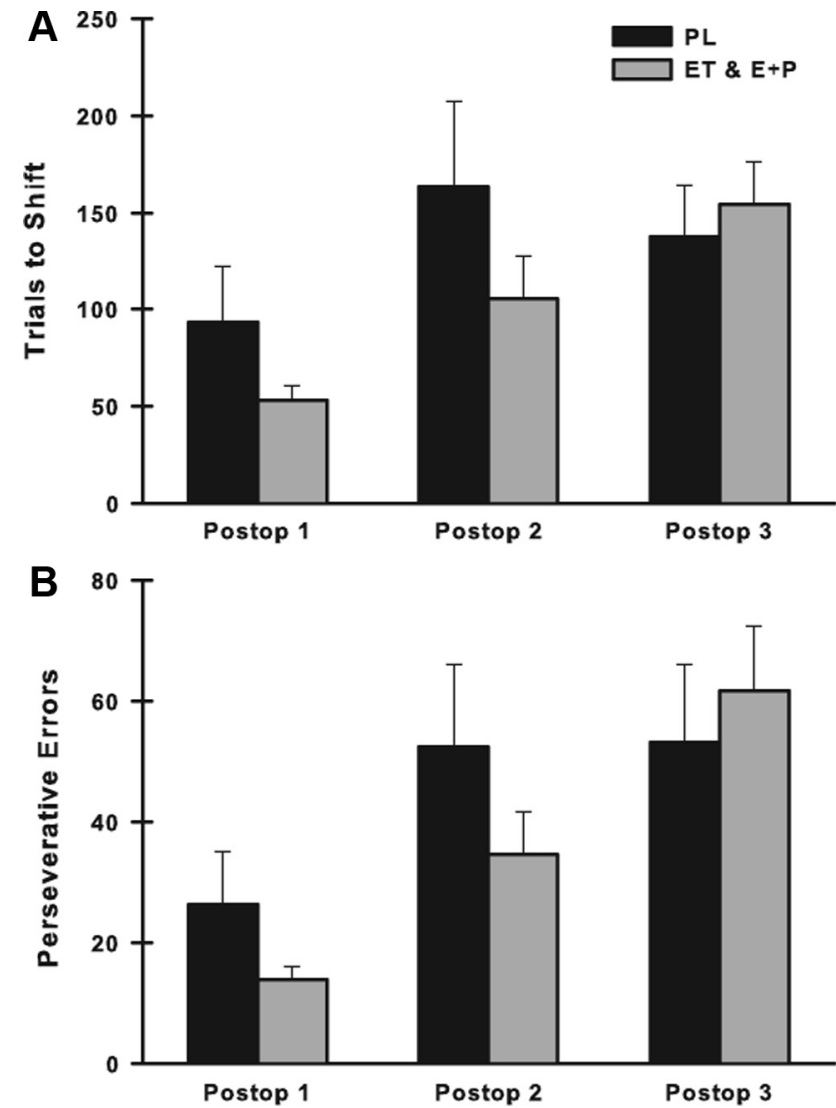

Figure 2. Conceptual set-shifting across the three postoperative evaluations. $\boldsymbol{A}, \boldsymbol{B}$, At the first postoperative assessment, placebo monkeys required twice as many trials to perform a conceptual shift $(\boldsymbol{A})$ and made more perseverative errors in shifting $(\boldsymbol{B})$ than the combined groups of estrogen therapy monkeys. Group effect sizes were only small to medium at the other evaluations. Error bars indicate SEM.

and shape (bow tie, cross, square) in preparation for learning the WCST. The stimuli appeared in a pseudo-random order on the monitor on each trial. The monkeys learned that touching the aqua box resulted in a reward being delivered. The correct stimulus remained the same from trial to trial. A $15 \mathrm{~s}$ intertrial interval (ITI) was used and learning criterion was $\geq 90 \%$ correct in a session of 100 trials. Once criterion was achieved, the animal was moved to the WCST the next testing day. Dependent measures for the three choice discrimination task were total number of trials and errors to achieve criterion.

The WCST itself consisted of two phases: (1) initial learning of a conceptual set, and (2) shifting of a conceptual set (Fig. 1). In both phases, three stimuli, differing in color and shape, appeared in a pseudo-random order in nine possible locations on the monitor on each trial. All possible combinations of stimuli were presented in a balanced randomized manner over a $4 \mathrm{~d}$ cycle and were repeated until criterion was achieved. During the initial conceptual set learning, the monkeys had to learn which stimulus dimension (color or shape) and which particular dimension examplar (the specific color or shape) was relevant to receive a reward. Touching the correct stimulus produced a pellet reward. Once the monkey touched the correct stimulus on 10 consecutive trials, the program changed the rewarded stimulus contingency during the same test session without the animal's knowledge (conceptual set-shift; from color to shape or vice versa). At the preoperative and postoperative assessments, the monkeys were tested for their ability to learn a new conceptual set and to perform one conceptual set-shift. At each of these assessments, colors and shapes were used that had never been used previously (Table 1). A 15 s ITI was used and each test session consisted of 100 trials. Criterion for both initial learning and shifting of a conceptual set was 10 consecutive correct responses. Dependent measures to learn the original conceptual set were the number of trials and errors to achieve 

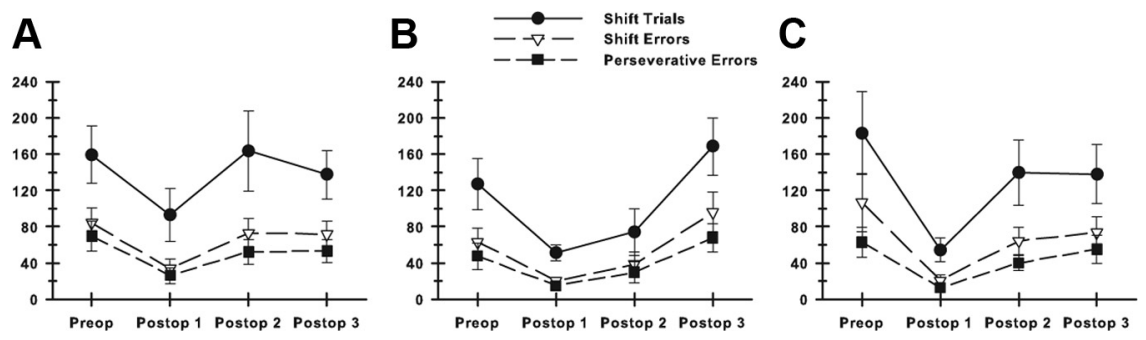

the observed differences between treatment groups (Cohen, 1988). The $d$ statistic is commonly used in trial planning and allows for evaluation of the size of an effect in a unit-less $\mathrm{SD}$ metric (i.e., outcomes of different measurement units can be directly compared using $d$ ). Reported in units of SD ranging from 0 (no group differences) to any positive number, a $d \leq 0.20$ represents small differences, $d=0.50$ represents medium differences, and $d>0.80$

Figure 3. Conceptual set-shifting within groups across evaluations. $\boldsymbol{A}-\boldsymbol{C}$, PL monkeys $(\boldsymbol{A}), \mathrm{ET}$ monkeys $(\boldsymbol{B}), \mathrm{E}+\mathrm{P}$ monkeys $(\boldsymbol{C})$. Differences in performance were found across evaluations for each group. See Results for details. Error bars indicate SEM.

represents large differences (although the clinical significance of an effect depends on what is actually being measured). Additional postoperative comparisons of interest identified a priori are also presented with group effect sizes.
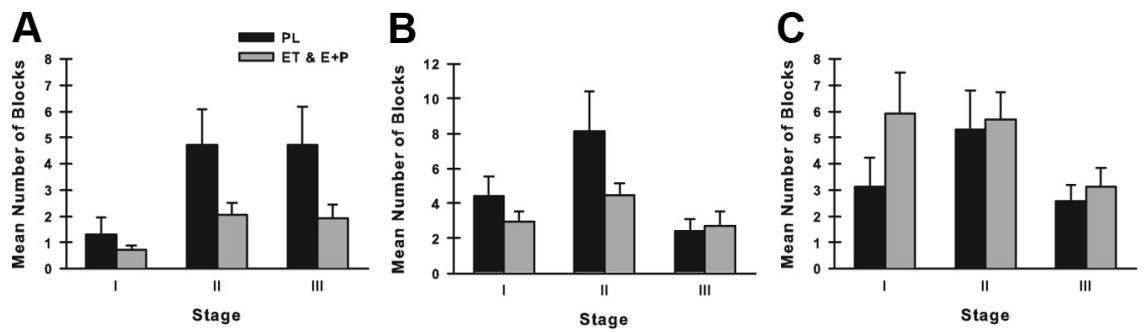

Figure 4. $\boldsymbol{A}-\boldsymbol{C}$, Stage performance during conceptual set-shifts at Postop $1(\boldsymbol{A})$, Postop $2(\boldsymbol{B})$, and Postop $3(\boldsymbol{C})$ assessments. Monkeys with PL spent significantly longer in stages II and III at Postop 1 and longer in stage II at Postop 2 than the combined groups of estrogen therapy monkeys. Error bars indicate SEM.

criterion. Dependent measures of shifting a conceptual set was the number of trials, number of errors, and number of perseverative errors (choosing of a stimulus containing a component of the previously rewarded category) to perform a shift.

VCRTT. The ability to orient and to shift visuospatial attention is assessed by this task (Posner, 1980). The procedure was similar to that described previously (Voytko et al., 1994; Baxter and Voytko, 1996; Voytko, 2002) and adapted for the touchscreen system. At the start of a trial, a white square appeared at the center of the monitor. The monkey was required to continuously touch the central square for $1-3 \mathrm{~s}$. At the end of the delay, one of two green circles ("cue") appeared to the left or right of the central square and was present for $200 \mathrm{~ms}$, during which time the monkey was required to continue touching the central square. After the $200 \mathrm{~ms}$, the central square was removed and a white square ("target") appeared on the left or right of the monitor. The correct strategy to receive a reward was to release touching the center of the monitor and to touch the target. Cues were valid (on the same side as where the target will appear), invalid (on the side opposite to where the target will appear), or neutral (both cue lights were illuminated as cues). Cues were valid in $\sim 70 \%$, invalid in $15 \%$, and neutral in $15 \%$ of the trials within a session. A 15 s ITI was used and each daily session consisted of 160 trials. Training on the VCRTT began with trials in which a target did not appear after the cue presentation. In these initial trials, monkeys received a reward for continually touching the central square while the cue was illuminated. Trials would be terminated and a $5 \mathrm{~s}$ time-out would occur if the monkey removed its hand from the center square prematurely. Valid, neutral, and invalid trials were introduced once an $85 \%$ level of accuracy was achieved in these training trials. Testing took place for $5 \mathrm{~d}$ for an approximate total of 560 valid trials, 120 invalid trials, and 120 neutral trials. The dependent measures were the time (in milliseconds) to release hold on the center of the monitor at target appearance (release time), validity (invalid - valid trials), benefits (neutral - valid trials), costs (invalid - neutral trials), and time (in milliseconds) to hit the target (hit time).

\section{Statistical analyses}

Data were initially analyzed with two-way measures of analyses of variance with group as a between-subjects factor and time as a repeated measures factor. To supplement the postoperative omnibus ANOVAs, a standardized measure of effect size, Cohen's $d$ [(Group A mean - Group B mean)/mean SD of Groups A and B], was calculated to index the size of
For the WCST, an additional analysis of conceptual set-shifting was conducted to evaluate whether particular stages of conceptual setshifting may be influenced by the experimental treatments based on similar analyses of reversal discrimination learning (Jones and Mishkin, 1972; Lai et al., 1995; Voytko, 1999). Two-way analyses of variance were conducted to compare groups for the number of blocks of 10 trials that were concentrated in 1 of 3 learning stages. Stage I (defined as performance where 7-10 errors were made in a 10-trial block) is the stage in which the animal is trying to disengage from the initial concept and overcome strong perseverative tendencies. Stage II (defined where $4-6$ errors were made in a 10-trial block) is the stage in which the animal is establishing the new stimulus-response association and is performing near chance levels. Stage III (defined where 0-3 errors were made in a 10-trial block) is the stage in which the animal is attaining acquisition criterion for the set-shift.

For each task, the ET and E+P groups were compared initially to determine whether these two HT groups differed. If these groups were equivalent in their performance, their data were combined into a single group of estrogen treated monkeys (E) and compared with the PL monkeys. If there were differences between the HT groups, then the ET and $\mathrm{E}+\mathrm{P}$ groups were each included in the comparison to PL monkeys. Within-group analyses were performed for the three individual treatment groups (PL, ET, E + P) with and without inclusion of the preoperative data so that comparisons could be made of data collected before and after ovariectomy/treatment, as well as only once treatment was initiated. Differences were considered significant at $p<0.05$. $p$ values of $0.05-1.0$ are listed to illustrate trends in the analyses.

\section{Results}

\section{Hormone levels}

We previously reported that serum levels of E2 and P4 achieved by our hormone regimen produced physiologic menstrual cycle levels of these hormones in these monkeys (ET: E2 implants = $69.3+2.9 \mathrm{pg} / \mathrm{ml}, \mathrm{E} 2$ injections $=545.47+27.7 \mathrm{pg} / \mathrm{ml} ; \mathrm{E}+\mathrm{P}: \mathrm{E} 2$ implants $=63.5+2.0$, E2 injections $=526.0+43.8 \mathrm{pg} / \mathrm{ml}, \mathrm{P} 4=$ $5.92+0.7 \mathrm{ng} / \mathrm{ml})$, that E2 levels were equivalent between the ET and $\mathrm{E}+\mathrm{P}$ monkeys, and that $\mathrm{E} 2$ levels were significantly greater in the $\mathrm{ET}$ and $\mathrm{E}+\mathrm{P}$ monkeys compared with the PL monkeys (E2 = $8.6+1.7 \mathrm{pg} / \mathrm{ml}, \mathrm{P} 4=<0.05 \mathrm{ng} / \mathrm{ml}$ ) (Voytko et al., 2008).

\section{WCST}

Preoperatively, groups of monkeys did not differ in their ability to learn the three choice discrimination task (trials or errors, $p$ values $>0.05$ ). In the WCST, monkeys that were eventually randomized to the ET group were slightly better in their ability to learn the first conceptual set than those destined to receive $\mathrm{E}+\mathrm{P}$ (but not PL) as based on number of errors to learn (group, $F_{(2,21)}=$ 

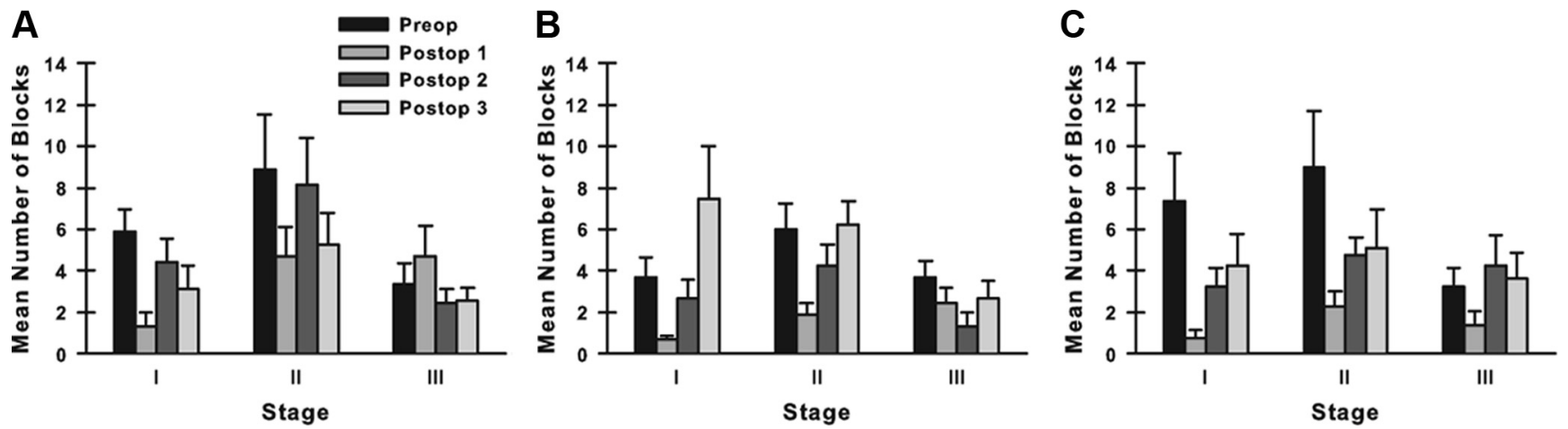

Figure 5. Within-group stage performance during conceptual set-shifts at the three postoperative assessments. $\boldsymbol{A}-\boldsymbol{C}$, PL monkeys (A), ET monkeys (B), E+P monkeys (C). Groups of monkeys spent different periods of time in different stages. See Results for details. Error bars indicate SEM.

3.74, $p=0.04$; Tukey posthocs: ET vs $\mathrm{E}+\mathrm{P}, p=0.04$; ET vs PL, $p>0.05$ ) but there was no difference between the groups based on number of trials to learn (group, $F_{(2,21)}=2.74, p>0.05$ ). The groups also did not differ preoperatively in their ability to perform a conceptual set-shift ( $p$ values $>0.05$ ).

Postoperatively, monkeys receiving ET or $\mathrm{E}+\mathrm{P}$ were equivalent in learning the original conceptual set and in performing a shift across assessments $(p>0.05)$. The scores of these two groups were combined (E group) and compared with those of the PL monkeys. The groups were comparable in their ability to learn the original concept across the postoperative evaluations as measured in either trials or errors (group, time, time $\times$ group, all $p$ values $>0.05$ ) and this also was reflected in the small group effect sizes (Table 2). In performing conceptual shifts, the omnibus ANOVA indicated that only the effect of time $\left(F_{(2,44)}=5.88, p<0.01\right)$ was significant for trials to shift (group and group $\times$ time, $p$ values $>0.05$ ). However, monkeys with PL required almost twice as many trials than the E monkeys to set-shift at the first postoperative assessment (Fig. $2 A)$ and indeed the group effect size $\left(d=0.74, F_{(1,22)}=\right.$ $3.47, p=0.07)$ at Postop \#1 indicated that there was a considerable difference between the treatment groups in number of trials to perform the conceptual set-shift. Group effect sizes (Table 2) for trials to shift were small to medium for the other postoperative assessments. For errors to perform the conceptual shift, only the effect of time was significant $\left(F_{(2,44)}=10.40, p<0.01\right.$ ) (group and group $\times$ time, $p$ values $>0.05$ ) and group effect sizes (Table 2 ) indicated only small to medium group differences for this dependent measure at each postoperative evaluation. For perseverative errors to shift, only the effect of time $\left(F_{(2,44)}=10.74, p<\right.$ 0.01 ) was significant (group and group $\times$ time, $p$ values $>0.05$ ). Here also, the group effect size $\left(d=0.76, F_{(1,22)}=3.59, p=0.07\right)$ at Postop \#1 was large indicating that monkeys with PL made more perseverative errors when performing the set-shift than the E monkeys (Fig. 2B).

Within-group analyses revealed that trials and errors to learn the initial concept were equivalent across assessments for each group ( $p$ values $>0.05$ for preop through postop or postop only). For the most part, similar patterns were seen for the three groups of monkeys in shifting conceptual sets across the three postoperative assessments. Monkeys with PL (Fig. 3A) differed across time for errors to shift (preop through postop: $F_{(3,18)}=5.75, \mathrm{p}=$
$<0.01$; postop: $\left.F_{(2,12)}=5.72, p=0.01\right)$ and for perseverative errors to shift (preop through postop: $F_{(3,18)}=4.77, p=0.01$; postop: $F_{(2,12)}=3.62, p=0.05$ ) but not for trials to shift (preop through postop or postop only, $p$ values $>0.05$ ). Monkeys with ET (Fig. $3 B$ ) differed across time for trials to shift (preop through postop: $F_{(3,24)}=7.25, p<0.01$; postop: $\left.F_{(2,16)}=11.25, p<0.01\right)$, errors to shift (preop through postop: $F_{(3,24)}=8.43, p<0.01$; postop: $\left.F_{(2,16)}=11.12, p<0.01\right)$, and perseverative errors to shift (preop through postop: $F_{(3,24)}=6.94, p<0.01$; postop: $F_{(2,16)}=10.17, p<0.01$ ). Monkeys with $\mathrm{E}+\mathrm{P}$ (Fig. $3 C$ ) differed across time for errors to shift (preop through postop: $F_{(3,21)}=2.88$, $p=0.06$; postop: $\left.F_{(2,14)}=3.52, p=0.05\right)$ and perseverative errors to shift (preop through postop: $F_{(3,21)}=2.83, p=0.06$; postop: $F_{(2,14)}=4.33, p=0.03$ ), but not for trials to shift (preop through postop or postop only, $p$ values $>0.05$ ).

Conceptual set-shift stage performance was equivalent between $\mathrm{ET}$ and $\mathrm{E}+\mathrm{P}$ monkeys across postoperative assessments ( $p$ values $>0.05$ ) and their combined scores were compared with those of the PL monkeys. The overall main effects of time $\left(F_{(2,44)}=3.80, p=0.03\right)$ and stage $\left(F_{(2,44)}=9.84, p<0.01\right)$ were significant, but not group $(p>0.05)$. The interactions of time $X$ group $\left(F_{(2,44)}=3.23, p=0.04\right)$ and time $\times$ stage $\left(F_{(4,88)}=4.07\right.$, $p<0.01)$ also were significant but other interactions were not. Subsequent analyses were conducted to further probe the time $\times$ group interaction. At Postop \#1 (Fig. 4A), significant effects of group $\left(F_{(1,22)}=6.99, p=0.01\right)$ and stage $\left(F_{(2,44)}=11.75, p<\right.$ $0.01)$, and a borderline significant interaction of stage $\times$ group $\left(F_{(2,44)}=2.41, p=0.10\right)$ were found. Large group effect sizes were found for stage II $\left(d=0.95, F_{(1,22)}=5.56, p=0.02\right)$ and stage III $\left(d=0.94, F_{(1,22)}=5.30, p=0.03\right)$ indicating that monkeys receiving PL required more blocks than E monkeys at these stages. In Postop \#2 (Fig. $4 B$ ), significant effects of stage $\left(F_{(2,44)}=\right.$ $12.25, p<0.01)$ and the interaction of stage $\times \operatorname{group}\left(F_{(2,44)}=\right.$ 
A

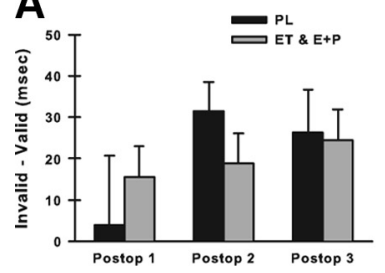

B

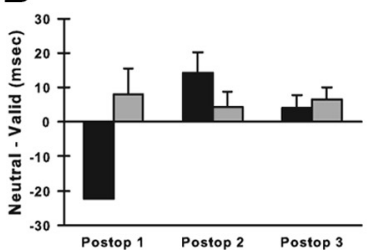

C

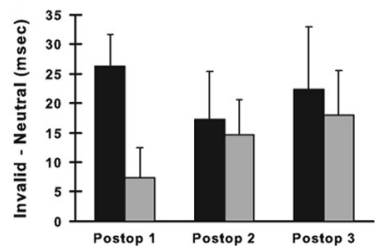

Figure 7. $\boldsymbol{A}-\boldsymbol{C}$, Measures of validity $(\boldsymbol{A})$, benefits $(\boldsymbol{B})$, and costs $(\boldsymbol{C})$ in PL-and estrogen-treated monkeys across the three postoperative assessments. Monkeys with PL had fewer benefits and greater costs than the combined groups of estrogen monkeys at the first postoperative assessment. Error bars indicate SEM.
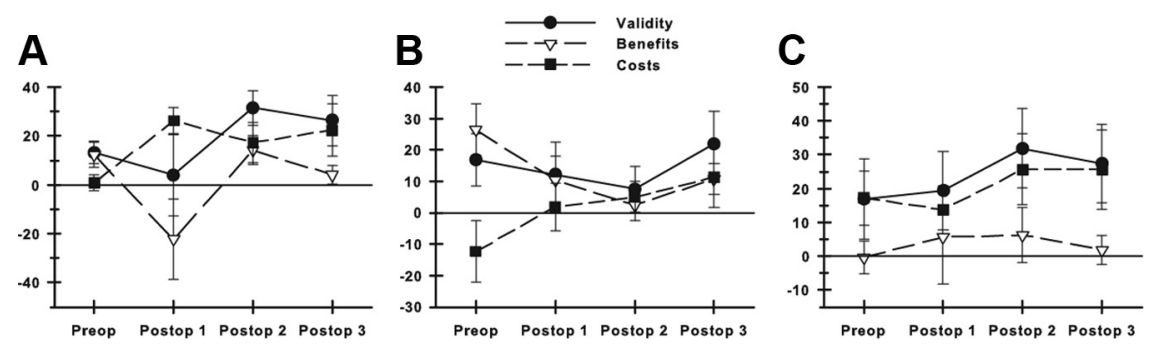

Figure 8. $\boldsymbol{A}-\boldsymbol{C}$, Within-group measures of validity, benefits, and costs in PL monkeys $(\boldsymbol{A}), \mathrm{ET}$ monkeys $(\boldsymbol{B})$, and $\mathrm{E}+\mathrm{P}$ monkeys (C) across assessments. Monkeys with PL significantly differed across evaluations in their benefits and costs. Monkeys with ET or $\mathrm{E}+\mathrm{P}$ did not vary significantly in measures across assessments. Error bars indicate SEM.

$3.25, p=0.04)$ were found. A large group effect size was found for stage II $\left(d=0.84, F_{(1,22)}=4.40, p=0.04\right)$ again indicating that monkeys with PL spent longer in this stage than E monkeys. There were no significant effects of group, stage, or stage $\times$ group for Postop \#3 (Fig. 4C) (all $p$ values $>0.05$ ) and group effect sizes for the three stages were only small to medium (Table 2 ) at this assessment.

Within-group analyses of stages of set-shifting indicated monkeys spent different periods of time at the different stages and in some cases, this varied across assessments. For monkeys with PL (Fig. 5A), a significant stage effect (preop through postop: $F_{(2,12)}=8.24, p<0.01$; postop: $\left.F_{(2,12)}=6.02, p=0.01\right)$ reflected the greater time spent in stage II and a time $X$ stage interaction (preop through postop: $F_{(6,36)}=2.60, p=0.03$; postop: $\left.F_{(4,24)}=3.09, p=0.03\right)$ reflected the change over time spent especially in stages I and II. For monkeys with ET (Fig. 5B), a significant stage effect (preop through postop: $F_{(2,16)}=4.13$, $p=0.03$; postop: $F_{(2,16)}=3.04 p=0.05$ ) reflected the greater time in stages I and II and a significant time effect (preop through postop: $F_{(3,24)}=11.35, p<0.01$; postop: $F_{(2,16)}=11.06, p<$ $0.01)$ reflected the variable performance over assessments. A time $\times$ stage interaction (preop through postop: $F_{(6,48)}=2.14$, $p=0.06$; postop: $F_{(4,32)}=2.63, p=0.05$ ) reflected the variable performance of monkeys with ET over time particularly in stages I and II. Stage analyses for $\mathrm{E}+\mathrm{P}$ monkeys (Fig. $5 C$ ) revealed differences across time (preop through postop: $F_{(3,21)}=2.77, p=0.06$; postop: $\left.F_{(2,14)}=2.78, p=0.09\right)$ and a time $\times$ stage interaction (preop through postop: $F_{(6,42)}=2.92, p=0.05$ ) indicated that time spent in stages I and II in particular decreased postoperatively.

\section{VCRTT}

Preoperatively, two monkeys were not able to learn the VCRTT and thus were not tested further on this task. Thus, 7 PL monkeys, 8 ET monkeys, and $7 \mathrm{E}+\mathrm{P}$ monkeys completed all evaluations of the VCRTT preoperatively and postoperatively. The three groups were comparable in the VCRTT preoperatively ( $p$ values $>0.05$ ). Comparisons of release time of the ET and E+P monkeys indi-

cated that there was a difference between these groups postoperatively (group, $\left.F_{(1,13)}=7.03, p=0.02\right)$, and thus, these estrogen groups were not combined to compare with PL monkeys for this dependent measure. In comparing the release time of the three treatment groups, only the main effect of trialtype was significant $\left(F_{(2,38)}=15.8, p<0.01\right)$. None of the other main effects or interactions were significant, including that of group (all $p$ values $>0.05$; data not shown). Time analyses for each group of monkeys indicated that the $\mathrm{E}+\mathrm{P}$ monkeys were slower postoperatively compared with their preoperative performance (Fig. 6C) (preop through postop: time, $F_{(3,18)}=3.12, p=$ $0.05)$, but they did not differ across their postoperative assessments (postop: time, $p>0.05)$. Neither PL or ET monkeys differed across assessments in their release time (Fig. 6A,B) (preop through postop or postop only, time, $p$ values $>0.05$ for both groups). Release time of all groups of monkeys differed across the types of trials (PL: preop through postop, $F_{(2,12)}=6.81$, $p=0.01$ and postop, $F_{(2,12)}=6.59, p=0.01$; ET: preop through postop, $F_{(2,14)}=3.72, p=0.05$ and postop, $F_{(2,14)}=3.27, p=$ 0.06 ; E+P: preop through postop, $F_{(2,12)}=5.53, p=0.02$ and postop, $\left.F_{(2,12)}=6.52, p=0.01\right)$. The three groups of monkeys did not differ in hit time across the postoperative assessments (all $p$ values $>0.05$ ) nor did hit time vary across time within each group of monkeys (all groups, $p>0.05$; data not shown).

Comparisons between the $\mathrm{ET}$ and $\mathrm{E}+\mathrm{P}$ groups indicated that the groups were comparable for validity $(p>0.05)$, benefits $(p>0.05)$, and costs $(p>0.05)$ and thus the two estrogen groups were combined into a collective E group of monkeys and compared with the PL monkeys. For measures of validity (Fig. $7 A)$, the main effect of time was significant $\left(F_{(2,40)}=3.37, p=\right.$ $0.04)$, but group or the interaction of time $X$ group was not significant (all $p$ values $>0.05$ ) and group effect sizes were only small to medium (Table 2). For measures of benefits (Fig. $7 B$ ), the main effect of time was borderline significant $\left(F_{(2,40)}=2.4, p=0.10\right)$ and the interaction of time $\times$ group was significant $\left(F_{(2,40)}=3.56\right.$, $p=0.03$ ). Subsequent analyses indicated that at the Postop \#1 assessment, PL monkeys demonstrated fewer benefits $(d=0.84$, $\left.F_{(1,20)}=3.87, p=0.06\right)$ than E monkeys. There were no significant differences in benefits between the treatment groups at Postop \#2 or Postop \#3 ( $p$ values $>0.05$ ) and the group effect sizes at these assessments were small to medium (Table 2). For measures of costs (Fig. 7C), the overall ANOVA did not indicate significant differences of group, time or time $\times$ group (all $p$ values $>0.05)$, however the substantial group effect size at Postop \#1 $\left(d=1.08, F_{(1,20)}=4.82, p=0.04\right)$ reflected that the PL monkeys had five times greater costs than the E monkeys at this assessment. The group effect sizes for measures of costs were small at the Postop\#2 and \#3 assessments (Table 2).

Within-group comparisons revealed that measures of validity did not differ significantly across assessments for PL monkeys (Fig. $8 A$ ) (preop through postop or postop only, $p$ values $>0.05$ ); however, PL monkeys differed across time in their benefits (Fig. $8 A$ ) (preop through postop: $F_{(3,18)}=3.02, p=0.05$; postop: $\left.F_{(2,12)}=2.89, p=0.09\right)$, reflecting a large decrease in benefits at 
their first postoperative assessment, and differed across time in their costs (Fig. 8A) (preop through postop: $F_{(3,18)}=2.59, p=0.08$; postop: $p>0.05$ ), reflecting an increase in costs postoperatively. Measures of validity, benefits, or costs did not vary significantly across time for the ET monkeys (Fig. $8 B$ ) (preop through postop or postop only, $p$ values $>0.05$ ) or for the $\mathrm{E}+\mathrm{P}$ monkeys (Fig. $8 C$ ) (preop through postop or postop only, $p$ values $>0.05$ ).

\section{Discussion}

The results of the present study indicate that shifting of cognitive set or visuospatial attention is impaired in middle-aged surgically menopausal monkeys that do not receive estrogen therapies compared with monkeys that receive therapy, and that these cognitive functions are equivalent between monkeys receiving estrogen alone or estrogen plus progesterone.

Compared with HT groups of monkeys, the PL monkeys were impaired in shifting their cognitive strategy in the WCST, measured by their conceptual set-shifting performance. Although PL monkeys did not have impairments in learning a new original conceptual set, the stage analyses revealed that the set-shifting impairments are related to difficulty learning the new conceptual set within the context of shifting sets; indicated by the greater amount of time PL monkeys spent in stages II and III compared with HT monkeys (Jones and Mishkin, 1972). Failure in cognitive set-shifting, as measured by the WCST or by the intradimensional/extradimensional task paradigm (Roberts et al., 1988), can be related to either the inability to release attention from a relevant perceptual dimension (perseveration, approximately to stage I) or from an inability to refocus attention to a previously irrelevant perceptual dimension that now has become relevant (approximately stages II and III) (Owen et al., 1993). Thus, the impairment in shifting cognitive set by the PL monkeys in the present study may be related to a difficulty in learning about previously irrelevant stimuli (Mackintosh, 1983). In contrast to the observations made in the present study, previous investigations reported that cognitive flexibility was unaffected by OVX or ET in older menopausal monkeys when measured either by the WCST or discrimination reversal tasks (Lacreuse et al., 2000, 2004), or in young adult OVX monkeys using discrimination reversal tasks (Voytko, 2000). One factor that could explain the difference between our findings and the previous studies in older menopausal monkeys is the significant difference in length of time from OVX to initiation of cognitive testing between the studies ( 2 weeks in present study vs mean of $\sim 15$ years in Lacreuse et al. studies); evidence is accumulating to suggest that there may be a critical menopausal period in which to observe effects (Maki, 2006; Genazzani et al., 2007; Sherwin and Henry, 2008). Moreover, we conducted a more detailed analysis of stages of conceptual set-shifting that permitted us to identify the component processes responsible for the impaired performance in the conceptual shifts.

Monkeys receiving PL demonstrated lowered benefits and higher costs postoperatively in the VCRRT compared with HT monkeys or to their preoperative measures. These results were related to the slower release times on valid and invalid trials compared with the neutral trials and indicate inefficient processing of the advanced cues in the task by PL monkeys. Our laboratory is the only one to have examined visuospatial attention in menopausal monkeys, and our observations here are similar to those of our study in young adult surgically menopausal monkeys where we found that PL monkeys also demonstrated significantly increased costs in the VCRRT, while ET monkeys had decreased costs (Voytko, 2002). Collectively, our observations in meno- pausal monkeys suggest that loss of estrogen disrupts component processes of visuospatial attention and that these effects are broader with advancing age.

Consistent with the observations made in the present study of menopausal monkeys, postmenopausal women receiving HT demonstrate better performance on the WCST than women not receiving therapy (Schmidt et al., 1996; Berman et al., 1997; Dunkin et al., 2005; Ghidoni et al., 2006; Erickson et al., 2007; Wegesin and Stern, 2007) (but see Pefanco et al., 2007). Although various measures of visuospatial (e.g., clock drawing, block design) or attention (e.g., visual search, vigilance) function have been assessed in postmenopausal women (for review, see Haskell et al., 1997; LeBlanc et al., 2001; Sherwin, 2002; Zec and Trivedi, 2002; Lethaby et al., 2008), the specific ability to shift visuospatial attention has not been measured. On the basis that our PL monkeys were impaired in attentional shifting, either among stimulus dimensions (WCST) or spatial dimensions (VCRTT), suggests that other measures of attentional shifting also may be altered in untreated postmenopausal women.

The prefrontal and parietal cortices form part of a frontoparietal attention network (Mesulam, 1981; Corbetta et al., 1993; Nobre et al., 1997, 2000; Hopf and Mangun, 2000; Hopfinger et al., 2001), and both of these cortical regions are involved in cognitive set-shifting (Owen et al., 1991; Dias et al., 1996; Birrell and Brown, 2000; Rogers et al., 2000; Fox et al., 2003) and shifting of visuospatial attention (Alivisatos and Milner, 1989; Petersen et al., 1989; Koski et al., 1998; Thiel et al., 2004; Vossel et al., 2006). Executive function and attention processes are altered with advancing age (Albert et al., 1990; Greenwood and Parasuraman, 1994, 2004; Parasuraman and Greenwood, 1998; Ridderinkhof et al., 2002; Fisk and Sharp, 2004) and performance on the WCST, in particular, is impaired beginning in middle-age in both humans (Gunning-Dixon and Raz, 2003) and monkeys (Moore et al., 2006). The structure and function of the prefrontal cortex is particularly sensitive to age-related changes in humans (Gur et al., 1987; Tisserand et al., 2002; Gunning-Dixon and Raz, 2003; Tumeh et al., 2007; Chee et al., 2009) and monkeys (Peters et al., 1994; Luebke et al., 2004; Cruz et al., 2009; Kabaso et al., 2009). In addition, the monkey prefrontal cortex, more than the parietal cortex, is especially sensitive to manipulation of ovarian hormones (Kritzer and Kohama, 1999; Gibbs et al., 2002; Tinkler et al., 2004; Wang et al., 2004), and this prefrontal sensitivity is observed in middle-aged and older monkeys (Hao et al., 2003, 2006; Kompoliti et al., 2004; Browne et al., 2009). Thus, the executive function and attentional changes that we noted in the middle-aged menopausal monkeys of the current study may be related to hormonal effects in the prefrontal region.

We recently reported that visual recognition memory in a delayed matching-to-sample task was impaired in middle-aged surgically menopausal monkeys receiving PL, but not HT (Voytko et al., 2008). The monkeys of that memory study are the same monkeys that were the subjects of this present set of investigations. Interestingly, the timeframe in which the impairment in visual memory in PL monkeys was observed in our initial studies, matches the timeframe in which PL monkeys displayed impairments of shifting both cognitive sets and spatial attention; i.e., deficits were evident within 3 months after OVX but no longer detectable by 6 months after surgery. In concert, our findings in these older menopausal monkeys indicate that aspects of memory, executive function, and attentional abilities are responsive to ovarian hormone manipulations, that this responsiveness occurs within a short time after removal of the ovaries, and that it is not long-lasting. Our observations are consistent with reports 
of beneficial effects of HT in these cognitive domains in postmenopausal women (Resnick and Maki, 2001; Smith et al., 2001; Erickson et al., 2007) and with the hypothesis that there may be a critical window in which to observe the benefits of HT (Maki, 2006; Genazzani et al., 2007; Sherwin and Henry, 2008). Because of similarities in reproductive, endocrine, and menopausal profiles to that of women, female monkeys are ideal animal models in which to investigate the effects of HT on cognitive function. Thus, continued studies in monkeys will be critical to further defining the cognitive changes that occur in menopause and identifying the most appropriate hormone therapies and regimens for maintaining and improving cognitive function of postmenopausal women.

\section{References}

Albert MS, Wolfe J, Lafleche G (1990) Differences in abstraction ability with age. Psychol Aging 5:94-100.

Alhola P, Polo-Kantola P, Erkkola R, Portin R (2006) Estrogen therapy and cognition: a 6-year single-blind follow-up study in postmenopausal women. Neurology 67:706-709.

Alivisatos B, Milner B (1989) Effects of frontal or temporal lobectomy on the use of advance information in a choice reaction time task. Neuropsychologia 27:495-503.

Baxter MG, Voytko ML (1996) Spatial orienting of attention in adult and aged rhesus monkeys (Macaca mulatta). Behav Neurosci 110:898-904.

Berg EA (1948) (1948) A simple objective test for measuring flexibility in thinking. J Gen Psychol 39:15-22.

Berman KF, Schmidt PJ, Rubinow DR, Danaceau MA, Van Horn JD, Esposito G, Ostrem JL, Weinberger DR (1997) Modulation of cognition-specific cortical activity by gonadal steroids: a positron-emission tomography study in women. Proc Natl Acad Sci U S A 94:8836-8841.

Binder EF, Schechtman KB, Birge SJ, Williams DB, Kohrt WM (2001) Effects of hormone replacement therapy on cognitive performance in elderly women. Maturitas 38:137-146.

Birrell JM, Brown VJ (2000) Medial frontal cortex mediates perceptual attentional set shifting in the rat. J Neurosci 20:4320-4324.

Browne C, Tobin JR, Voytko ML (2009) Effects of two years of conjugated equine estrogens on cholinergic neurons in young and middle-aged ovariectomized monkeys. Brain Res 1264:13-23.

Chee MW, Chen KH, Zheng H, Chan KP, Isaac V, Sim SK, Chuah LY, Schuchinsky M, Fischl B, Ng TP (2009) Cognitive function and brain structure correlations in healthy elderly East Asians. Neuroimage 46:257-269.

Cohen J (1988) Statistical power analysis for the behavioral sciences, Ed 2. Hillsdale, NJ: Earlbaum.

Corbetta M, Miezin FM, Shulman GL, Petersen SE (1993) A PET study of visuospatial attention. J Neurosci 13:1202-1226.

Cruz L, Roe DL, Urbanc B, Inglis A, Stanley HE, Rosene DL (2009) Agerelated reduction in microcolumnar structure correlates with cognitive decline in ventral but not dorsal area 46 of the rhesus monkey. Neuroscience 158:1509-1520.

Dias R, Robbins TW, Roberts AC (1996) Primate analogue of the Wisconsin Card Sorting Test: effects of excitotoxic lesions of the prefrontal cortex in the marmoset. Behav Neurosci 110:872-886.

Downs JL, Urbanski HF (2006) Neuroendocrine changes in the aging reproductive axis of female rhesus macaques (Macaca mulatta). Biol Reprod 75:539-546.

Dunkin J, Rasgon N, Wagner-Steh K, David S, Altshuler L, Rapkin A (2005) Reproductive events modify the effects of estrogen replacement therapy on cognition in healthy postmenopausal women. Psychoneuroendocrinology 30:284-296.

Erickson KI, Colcombe SJ, Elavsky S, McAuley E, Korol DL, Scalf PE, Kramer AF (2007) Interactive effects of fitness and hormone treatment on brain health in postmenopausal women. Neurobiol Aging 28:179-185.

Fedor-Freybergh P (1977) The influence of oestrogens on the wellbeing and mental performance in climacteric and postmenopausal women. Acta Obstet Gynecol Scand Suppl 64:1-91.

Fisk JE, Sharp CA (2004) Age-related impairment in executive functioning: updating, inhibition, shifting, and access. J Clin Exp Neuropsychol 26:874-890.
Fox MT, Barense MD, Baxter MG (2003) Perceptual attentional set-shifting is impaired in rats with neurotoxic lesions of posterior parietal cortex. J Neurosci 23:676-681.

Genazzani AR, Pluchino N, Luisi S, Luisi M (2007) Estrogen, cognition and female ageing. Hum Reprod Update 13:175-187.

Ghidoni R, Boccardi M, Benussi L, Testa C, Villa A, Pievani M, Gigola L, Sabattoli F, Barbiero L, Frisoni GB, Binetti G (2006) Effects of estrogens on cognition and brain morphology: involvement of the cerebellum. Maturitas 54:222-2288.

Gibbs RB, Nelson D, Anthony MS, Clarkson TB (2002) Effects of long-term hormone replacement and of tibolone on choline acetyltransferase and acetylcholinesterase activities in the brains of ovariectomized, cynomologus monkeys. Neuroscience 113:907-914.

Goodman AL, Descalzi CD, Johnson DK, Hodgen GD (1977) Composite pattern of circulating $\mathrm{LH}, \mathrm{FSH}$, estradiol, and progesterone during the menstrual cycle in cynomolgus monkeys. Proc Soc Exp Biol Med 155:479-481.

Greenwood PM, Parasuraman R (1994) Attentional disengagement deficit in nondemented elderly over 75 years of age. Neuropsychol Dev Cogn B Aging Neuropsychol Cogn 1:188-202.

Greenwood PM, Parasuraman R (2004) The scaling of spatial attention in visual search and its modification in healthy aging. Percept Psychophys $66: 3-22$.

Gunning-Dixon FM, Raz N (2003) Neuroanatomical correlates of selected executive functions in middle-aged and older adults: a prospective MRI study. Neuropsychologia 41:1929-1941.

Gur RC, Gur RE, Obrist WD, Skolnick BE, Reivich M (1987) Age and regional cerebral blood flow at rest and during cognitive activity. Arch Gen Psychiatr 44:617-621.

Hao J, Janssen WG, Tang Y, Roberts JA, McKay H, Lasley B, Allen PB, Greengard P, Rapp PR, Kordower JH, Hof PR, Morrison JH (2003) Estrogen increases the number of spinophilin-immunoreactive spines in the hippocampus of young and aged female rhesus monkeys. J Comp Neurol 465:540-550.

Hao J, Rapp PR, Leffler AE, Leffler SR, Janssen WG, Lou W, McKay H, Roberts JA, Wearne SL, Hof PR, Morrison JH (2006) Estrogen alters spine number and morphology in prefrontal cortex of aged female rhesus monkeys. J Neurosci 26:2571-2578.

Haskell SG, Richardson ED, Horwitz RI (1997) The effect of estrogen replacement therapy on cognitive function in women: a critical review of the literature. J Clin Epidemiol 50:1249-1264.

Hess DL, Spies HG, Hendrickx AG (1981) Diurnal steroid patterns during gestation in the rhesus macaque: onset, daily variation, and the effects of dexamethasone treatment. Biol Reprod 24:609-616.

Hopf JM, Mangun GR (2000) Shifting visual attention in space: an electrophysiological analysis using high spatial resolution mapping. Clin Neurophysiol 111:1241-1257.

Hopfinger JB, Woldorff MG, Fletcher EM, Mangun GR (2001) Dissociating top-down attentional control from selective perception and action. Neuropsychologia 39:1277-1291.

Jones B, Mishkin M (1972) Limbic lesions and the problem of stimulusreinforcement associations. Exp Neurol 36:362-377.

Kabaso D, Coskren PJ, Henry BI, Hof PR, Wearne SL (2009) The electrotonic structure of pyramidal neurons contributing to prefrontal cortical circuits in macaque monkeys is significantly altered in aging. Cereb Cortex. Advance online publication. Retrieved January 15, 2009. doi:10.1093/cercor/bhn242.

Kompoliti K, Chu Y, Polish A, Roberts J, McKay H, Mufson EJ, Leurgans S, Morrison JH, Kordower JH (2004) Effects of estrogen replacement therapy on cholinergic basal forebrain neurons and cortical cholinergic innervation in young and aged ovariectomized rhesus monkeys. J Comp Neurol 472:193-207.

Koski LM, Paus T, Petrides M (1998) Directed attention after unilateral frontal excisions in humans. Neuropsychologia 36:1363-1371.

Kritzer MF, Kohama SG (1999) Ovarian hormones differentially influence immunoreactivity for dopamine beta-hydroxylase, choline acetyltransferase, and serotonin in the dorsolateral prefrontal cortex of adult rhesus monkeys. J Comp Neurol 409:438-451.

Kurt M, Bekçi B, Karakaçs S (2006) Hormone replacement therapy and cognitive function in postmenopausal women. Maturitas 53:39-48.

Lacreuse A, Herndon JG, Moss MB (2000) Cognitive function in aged ovariectomized female rhesus monkeys. Behav Neurosci 114:506-513.

Lacreuse A, Chhabra RK, Hall MJ, Herndon JG (2004) Executive function is less sensitive to estradiol than spatial memory: performance on an analog 
of the card sorting test in ovariectomized aged rhesus monkeys. Behav Processes 67:313-319.

Lai ZC, Moss MB, Killiany RJ, Rosene DL, Herndon JG (1995) Executive system dysfunction in the aged monkey: spatial and object reversal learning. Neurobiol Aging 16:947-954.

LeBlanc ES, Janowsky J, Chan BK, Nelson HD (2001) Hormone replacement therapy and cognition: systematic review and meta-analysis. JAMA 285:1489-1499.

Lethaby A, Hogervorst E, Richards M, Yesufu A, Yaffe K (2008) Hormone replacement therapy for cognitive function in postmenopausal women. Cochrane Database Syst Rev 2008:CD003122.

Luebke JI, Chang YM, Moore TL, Rosene DL (2004) Normal aging results in decreased synaptic excitation and increased synaptic inhibition of layer $2 / 3$ pyramidal cells in the monkey prefrontal cortex. Neuroscience 125:277-288.

Mackintosh NT (1983) Conditioning and associative learning. Oxford: Clarendon.

Maki PM (2006) Hormone therapy and cognitive function: is there a critical period for benefit? Neuroscience 138:1027-1030.

McEwen BS (2001) Estrogens effects on the brain: multiple sites and molecular mechanisms. J Appl Physiol 91:2785-2801.

Mesulam MM (1981) A cortical network for directed attention and unilateral neglect. Ann Neurol 10:309-325.

Milner B (1963) Effects of different brain lesions on card sorting. Arch Neurol 9:90-100.

Moore TL, Killiany RJ, Herndon JG, Rosene DL, Moss MB (2005) A nonhuman primate test of abstraction and set shifting: an automated adaptation of the Wisconsin Card Sorting Test. J Neurosci Methods 146:165-173.

Moore TL, Killiany RJ, Herndon JG, Rosene DL, Moss MB (2006) Executive system dysfunction occurs as early as middle-age in the rhesus monkey. Neurobiol Aging 27:1484-1493.

Nobre AC, Sebestyen GN, Gitelman DR, Mesulam MM, Frackowiak RS, Frith CD (1997) Functional localization of the system for visuospatial attention using positron emission tomography. Brain 120:515-533.

Nobre AC, Gitelman DR, Dias EC, Mesulam MM (2000) Covert visual spatial orienting and saccades: overlapping neural systems. Neuroimage 11:210-216.

Owen AM, Roberts AC, Polkey CE, Sahakian BJ, Robbins TW (1991) Extra-dimensional versus intra-dimensional set shifting performance following frontal lobe excisions, temporal lobe excisions or amygdalohippocampectomy in man. Neuropsychologia 29:993-1006.

Owen AM, Roberts AC, Hodges JR, Summers BA, Polkey CE, Robbins TW (1993) Contrasting mechanisms of impaired attentional set-shifting in patients with frontal lobe damage or Parkinson's disease. Brain 116: $1159-1175$

Parasuraman R, Greenwood PM (1998) Selective attention in aging and dementia. In: The attentive brain. (Parasuraman R, ed), pp 461-487. Cambridge, MA: MIT.

Pefanco MA, Kenny AM, Kaplan RF, Kuchel G, Walsh S, Kleppinger A, Prestwood K (2007) The effect of 3-year treatment with $0.25 \mathrm{mg} /$ day of micronized 17beta-estradiol on cognitive function in older postmenopausal women. J Am Geriatr Soc 55:426-431.

Peters A, Leahu D, Moss MB, McNally KJ (1994) The effects of aging on area 46 of the frontal cortex of the rhesus monkey. Cereb Cortex 4:621-635.

Petersen SE, Robinson DL, Currie JN (1989) Influences of lesions of parietal cortex on visual spatial attention in humans. Exp Brain Res 76:267-280.

Polo-Kantola P, Portin R, Polo O, Helenius H, Irjala K, Erkkola R (1998) The effect of short-term estrogen replacement therapy on cognition: a randomized, double-blind, cross-over trial in postmenopausal women. Obstet Gynecol 91:459-466.

Posner MI (1980) Orienting of attention. Q J Exp Psychol 32:3-25.

Resnick SM, Maki PM (2001) Effects of hormone replacement therapy on cognitive and brain aging. Ann N Y Acad Sci 949:203-214.

Ridderinkhof KR, Span MM, van der Molen MW (2002) Perseverative behavior and adaptive control in older adults: performance monitoring, rule induction, and set shifting. Brain Cogn 49:382-401.

Roberts AC, Robbins TW, Everitt BJ (1988) The effects of intradimensional and extradimensional shifts on visual discrimination learning in humans and non-human primates. Q J Exp Psychol B 40:321-341.
Rogers RD, Andrews TC, Grasby PM, Brooks DJ, Robbins TW (2000) Contrasting cortical and subcortical activations produced by attentional-set shifting and reversal learning in humans. J Cogn Neurosci 12:142-162.

Rudolph I, Zimmermann T, Kaminski K, Jandova K, Borovsky B, Ahrendt HJ, Golbs S (2000) Changes in psychic and somatic well-being and cognitive capabilities of peri- and postmenopausal women after the use of a hormone replacement drug containing estradiol valerate and levonorgestrel. Methods Find Exp Clin Pharmacol 22:51-56.

Schmidt R, Fazekas F, Reinhart B, Kapeller P, Fazekas G, Offenbacher H, Eber B, Schumacher M, Freidl W (1996) Estrogen replacement therapy in older women: a neuropsychological and brain MRI study. J Am Geriatr Soc 44:1307-1313.

Sherwin BB (2002) Estrogen and cognitive aging in women. Trends Pharmacol Sci 23:527-534.

Sherwin BB, Henry JF (2008) Brain aging modulates the neuroprotective effects of estrogen on selective aspects of cognition in women: a critical review. Front Neuroendocrinol 29:88-113.

Smith YR, Giordani B, Lajiness-O’Neill R, Zubieta JK (2001) Long-term estrogen replacement is associated with improved nonverbal memory and attentional measures in postmenopausal women. Fertil Steril 76:1101-1107.

Thiel CM, Zilles K, Fink GR (2004) Cerebral correlates of alerting, orienting and reorienting of visuospatial attention: an event-related fMRI study. Neuroimage 21:318-328.

Tinkler GP, Tobin JR, Voytko ML (2004) Effects of two years of estrogen loss or replacement on nucleus basalis cholinergic neurons and cholinergic fibers to the dorsolateral prefrontal and inferior parietal cortex of monkeys. J Comp Neurol 469:507-521.

Tisserand DJ, Pruessner JC, Sanz Arigita EJ, van Boxtel MP, Evans AC, Jolles J, Uylings HB (2002) Regional frontal cortical volumes decrease differentially in aging: an MRI study to compare volumetric approaches and voxel-based morphometry. Neuroimage 17:657-669.

Tumeh PC, Alavi A, Houseni M, Greenfield A, Chryssikos T, Newberg A, Torigian DA, Moonis G (2007) Structural and functional imaging correlates for age-related changes in the brain. Semin Nucl Med 37:69-87.

Vanhulle G, Demol R (1976) A double-blind study into the influence of estriol on a number of psychological tests in post-menopausal women. In: Consensus on menopause research (Van Keep PA, Greenblatt A, Albeaux-Fernet M, eds), pp 94-99. London: MTP.

Vossel S, Thiel CM, Fink GR (2006) Cue validity modulates the neural correlates of covert endogenous orienting of attention in parietal and frontal cortex. Neuroimage 32:1257-1264.

Voytko ML (1999) Impairments in acquisition and reversals of two-choice discriminations by aged rhesus monkeys. Neurobiol Aging 20:617-627.

Voytko ML (2000) The effects of long-term ovariectomy and estrogen replacement therapy on learning and memory in monkeys. Behav Neurosci 114:1078-1087.

Voytko ML (2002) Estrogen and the cholinergic system modulate visuospatial attention in monkeys. Behav Neurosci 116:187-197.

Voytko ML, Olton DS, Richardson RT, Gorman LK, Tobin JR, Price DL (1994) Basal forebrain lesions in monkeys disrupt attention but not learning and memory. J Neurosci 14:167-186.

Voytko ML, Higgs CJ, Murray R (2008) Differential effects on visual and spatial recognition memory of a novel hormone therapy regimen of estrogen alone or combined with progesterone in older surgically menopausal monkeys. Neuroscience 154:1205-1217.

Wang J, Cheng CM, Zhou J, Smith A, Weickert CS, Perlman WR, Becker KG, Powell D, Bondy CA (2004) Estradiol alters transcription factor gene expression in primate prefrontal cortex. J Neurosci Res 76:306-314.

Wegesin DJ, Stern Y (2007) Effects of hormone replacement therapy and aging on cognition: evidence for executive dysfunction. Neuropsychol Dev Cogn B Aging Neuropsychol Cogn 14:301-328.

Woolley CS (2007) Acute effects of estrogen on neuronal physiology. Annu Rev Pharmacol Toxicol 47:657-680.

Zec RF, Trivedi MA (2002) The effects of estrogen replacement therapy on neuropsychological functioning in postmenopausal women with and without dementia: a critical and theoretical review. Neuropsychol Rev 12:65-109. 